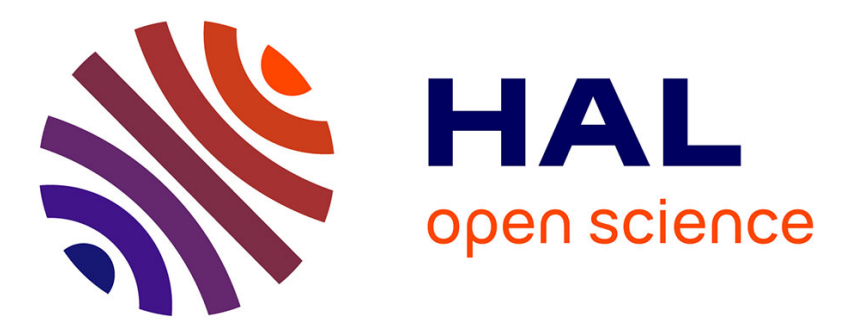

\title{
Fitness consequences of low temperature storage of Aphidius ervi
}

Mohannad Ismail, Joan van Baaren, Valérie Briand, Jean-Sébastien Pierre, Philippe Vernon, Thierry Hance

\section{- To cite this version:}

Mohannad Ismail, Joan van Baaren, Valérie Briand, Jean-Sébastien Pierre, Philippe Vernon, et al.. Fitness consequences of low temperature storage of Aphidius ervi. BioControl, 2014, 59 (2), pp.139148. 10.1007/s10526-013-9551-x . hal-00999550

\section{HAL Id: hal-00999550}

\section{https://hal-univ-rennes1.archives-ouvertes.fr/hal-00999550}

Submitted on 5 Sep 2014

HAL is a multi-disciplinary open access archive for the deposit and dissemination of scientific research documents, whether they are published or not. The documents may come from teaching and research institutions in France or abroad, or from public or private research centers.
L'archive ouverte pluridisciplinaire HAL, est destinée au dépôt et à la diffusion de documents scientifiques de niveau recherche, publiés ou non, émanant des établissements d'enseignement et de recherche français ou étrangers, des laboratoires publics ou privés. 


\section{Fitness consequences of low temperature storage of Aphidius ervi}

Mohannad Ismail (1) (3), Joan van Baaren (1), Valérie Briand (1), Jean-Sébastien Pierre (1), Philippe Vernon (2), Thierry Hance (3)

1. UMR 6553 CNRS - EcoBio, Université de Rennes 1, 263 Avenue du Général Leclerc, CS74205, 35042, Rennes Cedex, France

3. Earth and Life Institute, Biodiversity Research Centre, Université catholique de Louvain, Louvain-la-Neuve, Belgium

2. Station Biologique de Paimpont, UMR 6553 CNRS - EcoBio, Université de Rennes 1, Paimpont, France 


\begin{abstract}
In biological control programs, storage at low temperatures is used to produce large number of individuals before inundative releases. However, an exposure to low temperatures may affect the survival of exposed individuals and some life history traits such as the daily fecundity or the longevity of the survivors. This impact on life history traits is important because they will determine the growth potential of the population. To estimate the costs of different treatments of low temperature exposure, we analyzed the main instantaneous demographic parameters of the parental generation of Aphidius ervi Haliday (Hymenoptera: Braconidae) when exposed to three storage temperatures $\left(7,4\right.$ and $\left.0^{\circ} \mathrm{C}\right)$, combined with two storage durations ( 1 and 2 weeks) and two thermal regimes (constant and fluctuating), which represents a total of 12 treatments and a control.
\end{abstract}

The average cohort generation time (Tc) decreased significantly after exposure to low temperature, particularly in fluctuating treatments. This means that development continues during storage. Cumulative fecundity and the net reproductive rate $\left(\mathbf{R}_{\mathbf{0}}\right)$ decreased significantly for most of the storage treatments. This decrease was most pronounced in the constant temperature treatments. Females under fluctuating thermal regime produced a higher cumulative fecundity than those exposed to constant temperatures. Surprisingly, an exposure to $0^{\circ} \mathrm{C}$ over one week did not affect emergence rate and fecundity whereas all other treatments did.

Storage at low temperatures may affect the efficiency of inundative releases, with the exception of storage for one week at $0^{\circ} \mathrm{C}$. Moreover, cumulative fecundity and net reproductive rate $\left(\mathbf{R}_{\mathbf{0}}\right)$ represent a more immediate prediction of the increase of the population after low temperature exposure than the intrinsic rate of increase $\left(\mathbf{r}_{\mathbf{m}}\right)$, and reflect the qualities required in an inundative release context.

Keywords: Aphidius ervi, low temperature exposure, cumulative fecundity, intrinsic rate of 
increase, net reproductive rate, sex-ratio, trade-off.

\section{Introduction}

Demographic studies of population size and density, age distribution, and pattern of growth can be used to elucidate biological traits such as genetic structure, behaviour and ecology, which is necessary to predict the growth or decline of a population (Andrewartha and Birch 1954; Chi 1988; Price et al. 2011). These studies are important tools that provide comprehensive data on the survival, development time, longevity of adults, and the reproduction capabilities of each female (Yang and Chi 2006; Yu et al. 2013). Demographic analysis of various life history parameters has been applied on a variety of organisms including a large number of insect species (e.g. Blanco et al. 2009; Chi 1988; Yang and Chi 2006) and the natural enemies of agricultural pests (Amir-Maafi and Chi 2006; Atlihan and Chi 2008; Chi and Su 2006; Nunez-Campero et al. 2012). They allow growth predictions based on population models to be developed (Carey 1993) and may help to forecast both the effectiveness of a parasitoid in the field (Ehler 1990) and its interactions with insect pests and competitors of natural enemies (Omer et al. 1996; Roy et al. 2003).

Temperature is one of the most important climatic conditions affecting survival, development, phenology, reproduction, sex-ratio, dispersal, population growth and thus abundance (Amiri et al. 2010; Angilletta 2009; Hance et al. 2007; Omer et al. 1996). Several papers described the effect of high and low temperatures on insect life history traits (e.g. Ismail et al. 2010; Mawela et al. 2013; Moiroux et al. 2013). Low temperatures were used in the field of biological control in order to produce simultaneously a large amount of natural enemies, available when they are necessary (Bueno and van Cleave 1997). There are however few studies that investigate the consequences of exposure of specific developmental stages to low temperatures and the impact this exposure could have on the phenotypic plasticity of the 
individual traits that determines the growth of populations (Chen et al. 2011; Chen et al. 2008a; Chen et al. 2008b). Such exposure is regularly practiced in mass rearing of insects used in biological control (Leopold et al. 1998). Under these conditions, cumulative damages due to storage can occur and the expression of fitness traits can be effected (see Colinet and Boivin 2011 for a review). However, most of the publications examining the effects of storage at low temperatures evaluate some specific fitness traits (van Baaren et al. 2005), without evaluating the overall consequences for the population. From an agronomic point of view, the question is: how to evaluate the number of reproductive females that can be produced by a generation of stored individuals? Several indicators can be used, such as the net reproductive rate $\left(\mathbf{R}_{\mathbf{0}}\right)$ and the intrinsic rate of increase $\left(\mathbf{r}_{\mathbf{m}}\right)$ calculated on the basis of survival, fertility, development time and sex-ratio of offspring (Andrewartha and Birch 1954; Carey 1993; Nunez-Campero et al. 2012), as well as the cumulative fecundity (Chen et al. 2011; Hance et al. 1994; Kennedy et al. 1996). The novelty of our study was to compare the different parameters representing the population growth rate.

In this framework, our goal was to analyse the effect of low temperature exposure on the parasitoid Aphidius ervi (Haliday) (Hymenoptera: Braconidae) for one and two week periods when still inside its host at the mummy stage. We chose three temperatures above and below the development threshold $\left(\mathbf{T}_{\mathbf{0}}=6.6^{\circ} \mathrm{C}\right)$ (Sigsgaard 2000). Our assumptions are: 1) demographic parameters will be affected by low temperatures and exposure time, 2) the development of the mummy is expected to continue at the temperature above $\mathbf{T}_{\mathbf{0}}$ and thus the emergence after exposition should be faster than temperatures that are below $\mathbf{T}_{\mathbf{0}}$. 3) Previous studies have shown that fluctuating temperatures are less stressful than the constant ones, when the effect of low temperature storage was measured on different life-history traits (Colinet et al. 2006; Ismail et al. 2013; Ismail et al. 2010). We predict that fluctuating temperatures will allow better resistance to 
exposure to low temperatures, and this should result in the demographic parameters being affected less than under constant temperatures. The purpose of this study was also to determine the best parameters to compare the effects of different treatments of storage on the growth rate of the generation exposed (i.e. the generation which will be released in the field).

\section{Materials and methods}

The parasitoid $A$. ervi was chosen as a model because it is commercially produced and widely distributed in several European countries for inundative releases (Boivin et al. 2012; Stilmant et al. 2008). The colonies of $A$. ervi and the grain aphid Sitobion avenae Fabricius (Homoptera: Aphididae) were maintained in the laboratory as described and explained in Ismail et al. (2010) and Ismail et al. (2012).

To determine the consequence of a low temperature exposure on the demographic parameters of $A$. ervi, we chose three temperatures: $7^{\circ} \mathrm{C}$ is just above the mummy-adult development threshold $\left(\mathbf{T}_{\mathbf{0}}=6.6^{\circ} \mathrm{C}\right)$ for A. ervi (Sigsgaard 2000$), 4^{\circ} \mathrm{C}$ is just below the $\left(\mathbf{T}_{\mathbf{0}}\right)$ and $0^{\circ} \mathrm{C}$ above a potential freezing temperature. Two durations were used to store the mummies: 1 or 2 weeks, under two thermal regimes: constant storage temperature $(\mathrm{C})$, or fluctuating storage temperature $(\mathrm{F})$. For the fluctuating treatments a daily interruption of 2 hours at $20^{\circ} \mathrm{C}$ was practiced as described by Colinet et al. (2006).

One-day-old mummies of $A$. ervi were taken from the rearing colony three days per week and were randomly assigned to the control at $20^{\circ} \mathrm{C}$ or to one of the 12 storage treatments as described in Table 1. We used three identical incubators for the treatments (Sanyo MIR 153, Electric Co. Ltd, Japan) with a thermal precision of $\pm 1{ }^{\circ} \mathrm{C}$, under a photoperiod 16L: 8D, and humidity $60 \pm 10 \%$, and to avoid an incubator effect, a portion of the mummies of each treatment was exposed in each of the incubators. 
For the 12 treatments, mummies were progressively acclimated by exposing them to $20^{\circ} \mathrm{C}$ and then reducing the temperature by steps over a 2 hour period (for $7^{\circ} \mathrm{C}$ : $2 \mathrm{~h}$ at 17,14 and $11^{\circ} \mathrm{C}$; $4^{\circ} \mathrm{C}: 2 \mathrm{~h}$ at 16,12 and $8^{\circ} \mathrm{C} ; 0^{\circ} \mathrm{C}: 2 \mathrm{~h}$ at 15,10 and $5^{\circ} \mathrm{C}$ ) (Levie et al. 2005). After the exposure to low temperatures, mummies were transferred to $20^{\circ} \mathrm{C}$ using the opposite progressive temperature steps as for the low temperature exposure. In the control treatment and after each storage treatment, each mummy was individually placed in separate small gelatin capsules $(\varnothing=0.5 \mathrm{~cm}$, $\mathrm{L}=1.5 \mathrm{~cm})$. The following life history traits were measured after each storage treatment:

\section{Emergence rate}

Adult emergence rate was expressed as the percentage of individuals that emerged from control and stored mummies in each gelatin capsule. Emergence was recorded daily early in the morning.

\section{Fecundity parameters}

After emergence, one-day-old females were placed with one-day-old males from the same treatment in a Petri dish for 15 minutes, and they were observed until mating occurred. Females were then individually transferred to small caged pots containing a wheat plant with about 100 aphids of $3^{\text {rd }}$ and $4^{\text {th }}$ nymphal instars. The number of females used for each treatment is given in Tables 2 and 3 . This experiment was carried out at $20 \pm 1^{\circ} \mathrm{C}$ with a $16 \mathrm{~L}: 8 \mathrm{D}$ photoperiod. Since females usually lay their eggs at the beginning of their life, these pots were renewed every day during the five first days and then once every three days until the death of the female. The females were fed with honey ad libitum. Mortality of these females was checked daily from the first day of the experiment until their death. Daily fecundity was evaluated by counting the number of mummies obtained. 
Demographic growth parameters of parental generation

The following parameters were measured in order to construct the life tables: development time (from oviposition to adult emergence), daily female fecundity (number of females produced per female) and female longevity. In the calculation of these parameters, the storage duration was subtracted from the total time spent under the mummy stage. Indeed, for practical purposes, the most important feature for control of the agronomic pest is the time needed for adults to emerge after the storage. However, in this case, development time for individuals exposed to temperatures above the $\left(\mathbf{T}_{\mathbf{0}}\right)$ or under fluctuating regimes was probably underestimated as development was still possible at that temperature.

The intrinsic rate of increase $\left(\mathbf{r}_{\mathbf{m}}\right)$ was determined by solving numerically the Birth's approximation of Lotka's equation (Birch 1948; Carey 1993): $\sum \mathbf{l}_{\mathbf{x}} \cdot \mathbf{m}_{\mathbf{x}} \cdot \mathbf{e}^{-\mathbf{r x}}=\mathbf{1}$, where $x$ is the age class, $\mathbf{l}_{\mathbf{x}}$ the probability of survival till class $x$, and $\mathrm{m}_{\mathrm{x}}$ the fecundity of the class $x$. The generation time (Tc) was calculated as the mean interval separating the birth of one generation from the birth of the next one, as: $\mathbf{T c}=\sum\left(\mathbf{l}_{\mathbf{x}} \cdot \mathbf{m}_{\mathbf{x}} \cdot \mathbf{x}\right) / \sum \mathbf{I}_{\mathbf{x}} \cdot \mathbf{m}_{\mathbf{x}}$. The net reproductive rate $\left(\mathbf{R}_{\mathbf{0}}\right)$, represented the mean number of female offspring produced by each female during its entire life (Birch 1948; Carey 1993), and was calculated as: $\mathbf{R}_{\mathbf{0}}=\sum \mathbf{l}_{\mathbf{x}} \cdot \mathbf{m}_{\mathbf{x}}$.

We used the jackknife technique to estimate the mean demographic parameters and the standard errors (SE) of the demographic parameters of the life table as previously used by Meyer et al. (1986) and Chen et al. (2008a, b). The Jackknife analysis method removes one observation at a time from the original data set and recalculates the statistic of interest from the truncated data set as follow: $\check{\mathbf{r}}_{\mathbf{i}}=\mathbf{n} \cdot \mathbf{r}_{\text {all }}-(\mathbf{n}-\mathbf{1}) \cdot \mathbf{r}_{\mathbf{i}}$, where $\mathrm{n}$ is the number of females, $\mathrm{r}_{\text {all }}$ is the pseudovalue for all females and $\mathbf{r}_{\mathbf{i}}$ is the pseudovalue for each female individual in turn. These values are referred to as pseudovalue (Efron 1989). The values of $\mathbf{r}_{\mathbf{m}}$ per female and per temperature were calculated by using the software Microsoft Excel and its numerical solver. The method can 
estimate $\mathbf{T c}, \mathbf{R}_{\mathbf{0}}$ and $\mathbf{r}_{\mathbf{m}}$ with their respective jackknife variances.

Progeny sex-ratio

The mummies of the F1 generation were placed in a plastic Petri dish until emergence in order to determine the sex-ratio of the progeny (the number of females divided by the number of males).

Statistical analyses

The emergence rates were compared between treatments using a $\chi^{2}$ test. Curves of cumulative fecundities were calculated according to the model of Von Bertalanffy in weight (VBM, Von Bertalanffy, 1934): $\mathrm{Y}=\mathrm{K}^{*}\left(1-\exp \left(-\mathrm{a}^{*} \mathrm{x}\right)\right)^{\wedge} 3$, where $\mathrm{Y}$ represents the value of the cumulative fecundity at age $\mathbf{x}, \mathbf{K}$ is the maximum number of offspring per female (plateau value), and $\mathbf{a}$ is the parameter which governs the inflection point $(\log (3) / a)$. Von Bertalanffy's model in weight is suitable for representing the evolution of mass of a growing organism or of a part of it. VBM were fitted by non-linear least squares (nls function in $R$ ) and compared through their two parameters $\mathbf{a}$ and $\mathbf{K}$, whose standard error estimators are provided. An overall $\mathrm{F}$ test in $\mathrm{R}$ language was written, for a given parameter subject to one or several factors, and then applied to Bonferroni's test in order to compare the parameters two by two. As the control level has a single modality for the duration of storage and for the thermal regime, the duration of storage and the temperature of storage is to be considered as nested inside the thermal regime (nesting factor with three levels: control, constant temperature, fluctuating temperature), as well as their interaction. Tc, considered as a time delay, was analyzed by Cox Proportional Hazard Model including temperature, storage duration and thermal regime as fixed factors. $\mathbf{R}_{\mathbf{0}}$ and $\mathbf{r}_{\mathbf{m}}$ were analyzed by Generalized Linear models with the Gaussian family, equivalent to classical analysis of variance, including temperature, storage duration and thermal regime as fixed factors. Progeny sex-ratio 
was analyzed by Generalized Linear models, including temperature, storage duration and thermal regime as fixed factors. Sex-ratio was considered as a binomial variable and thus under the logistic family with logit link. When there were interactions among the factors, we considered all combinations of storage temperature and storage duration in pairwise comparisons and each against the control. The total is therefore $13 \times 6=78$ comparisons. For $\mathbf{R}_{\mathbf{0}}$, a Tukey Honest Significant Difference test was used because there is an appropriate compromise between power and conservativeness in this test. For the other parameters, Bonferroni's post hoc multiple comparison tests were used ( $\alpha=0.05 \mathrm{k}^{-1}$, where $\mathrm{k}$ is the number of comparisons, here 78 ). Data are presented as means $( \pm \mathrm{SE})$. Statistical analyses were done using the statistical package $\mathrm{R}$ version 2.8.0 (R Development Core Team, 2008).

\section{Results}

\section{Emergence rate}

The emergence rate of $A$. ervi varied from 80 to $95 \%$ under the low temperature treatments and reached $97 \%$ in the control (Table1). The lowest value $(80 \%)$ was obtained under constant exposure over two weeks at $0^{\circ} \mathrm{C}(0 \mathrm{C} 2)$. However, no statistical difference was recorded among the 13 treatments $\left(\chi^{2} 12=3.10, p=0.995\right)$.

Cumulative fecundity of parental generation

The analysis of cumulative fecundity using the model of Von Bertalanffy comparing the sigmoid curves presented significant differences among treatments $\left(F_{24,1302}=82.20, p<0.001\right)$. Only females exposed at $0^{\circ} \mathrm{C}$ for one week duration of storage $(0 \mathrm{C} 1: \mathrm{K}=54.66$ and $\mathrm{a}=2.50$ days with progeny sex-ratio: 0.57 females $)$ showed a comparable value to the control $(\mathrm{K}=52.88$ and $\mathrm{a}=$ 2.72 days with progeny sex-ratio: 0.57 females) (Table 2). All tested females produced offspring 
after the storage at low temperatures except a single female in treatment $4 \mathrm{C} 2$. The inflection point (a) of the fecundity curves indicates that the peak of fecundity is much earlier in the 4C2 and 0F1 treatments (1.82 days and 1.86 respectively) illustrating a more rapid population growth than in the control (2.72 days) or the treatment 0F2 (3.41 days) but this is compensated by a reduced total fecundity (K value).

Demographic growth parameters of parental generation

The significant differences in demographic parameters of $A$. ervi for the different treatments are presented in Table 3. The generation time (Tc) decreased significantly under storage temperatures at 7 and $4^{\circ} \mathrm{C}$ compared to the control (Cox proportional hasard model: $\chi^{2}{ }_{4}=215.55$, $\mathrm{p}<0.001)$ and according to both durations of storage $\left(\chi^{2}{ }_{2}=23.57, \mathrm{p}<0.001\right)$. It was also shorter under the fluctuating regime $\left(\chi_{2}^{2}=58.60, p<0.001\right)$. There was a significant three-way interaction among the three tested factors $\left(\chi_{27}^{2}=165.43, p<0.001\right)$. However, the interaction was weak and indicated a reduction of Tc for all modalities. However, the Tc of the fluctuating treatments decreased more sharply at $4{ }^{\circ} \mathrm{C}$ than for the constant treatments. The mean generation time in control treatment was 17.44 days. The longest generation time was observed in the two treatments at $0^{\circ} \mathrm{C}(0 \mathrm{C} 1=17.32$ and $0 \mathrm{C} 2=17.52$ days $)$, whereas the shortest generation time (14.14 days) was under the treatment 7F2.

The growth reproductive rate $\left(\mathbf{R}_{\mathbf{0}}\right)$ ranged from 31.49 to 47.47 at $7^{\circ} \mathrm{C}$, from 27.86 to 41.33 at $4{ }^{\circ} \mathrm{C}$, and from 37.42 to 54.92 at $0^{\circ} \mathrm{C}$. The effects of thermal regime $\left(F_{2,132}=235.28, p<\right.$ $0.001)$, storage temperature nested to thermal regime $\left(F_{4,132}=68.03, p<0.001\right)$, storage duration nested to thermal regime $\left(F_{2,132}=15.86, p<0.001\right)$ and the interaction storage temperature storage duration $\left(F_{4,132}=72.19, p<0.001\right)$ were all highly significant (Table 2$)$. The control was not significantly different from the $0 \mathrm{C} 1$, which provided the highest $\mathbf{R}_{\mathbf{0}}$, and both the control and 
the $0 \mathrm{C} 1$ were significantly higher than all the other treatments. In evaluating the effect of fluctuating regime relatively to the constant one, we found four cases weekly interacting, where the $\mathrm{R}_{0}$ was higher in fluctuating regime than in constant regime $(7 \mathrm{C} 1-7 \mathrm{~F} 1,7 \mathrm{C} 2-7 \mathrm{~F} 2,4 \mathrm{C} 1-4 \mathrm{~F} 1$ and $4 \mathrm{C} 2-4 \mathrm{~F} 2)$, a case with no significant difference $(0 \mathrm{C} 2-0 \mathrm{~F} 2)$, and a case where fluctuating temperatures strongly depleted the $\mathbf{R}_{\mathbf{0}}(0 \mathrm{C} 1-0 \mathrm{~F} 1)$. The reaction to storage temperature depends strongly of the combination of the temperature regime (fluctuating or constant) and storage duration. For one week storage at constant temperature, the $\mathbf{R}_{\mathbf{0}}$ decreased significantly from $0^{\circ} \mathrm{C}$ to $4^{\circ} \mathrm{C}$ and then increased slightly but significantly at $7^{\circ} \mathrm{C}$. Conversely, under fluctuating regime, the $\mathbf{R}_{\mathbf{0}}$ was low at $0^{\circ} \mathrm{C}$, remained steady at $4^{\circ} \mathrm{C}$ and increased strongly at $7^{\circ} \mathrm{C}$. For two weeks storage under constant and fluctuating conditions, the $\mathbf{R}_{\mathbf{0}}$ was not significantly different at $0^{\circ} \mathrm{C}$ and $4^{\circ} \mathrm{C}$ but decreased strongly from $4^{\circ} \mathrm{C}$ to $7^{\circ} \mathrm{C}$.

The intrinsic growth rate $\left(\mathbf{r}_{\mathbf{m}}\right)$ only showed a slight effect of thermal regime $\left(F_{1,118}=4.16\right.$, $p=0.04$ ) when the control level is dropped from the analysis. The $\mathbf{r}_{\mathbf{m}}$ did not vary significantly with the storage temperatures $\left(F_{4,118}=0.31, p=0.87\right)$, nor with storage durations $\left(F_{2,118}=1.41, p\right.$ $=0.25)($ Table 2$)$ and no interaction was found among these factors $\left(F_{4,118}=1.27, p=0.29\right)$. The slight effect of thermal regime showed a better $\mathbf{r}_{\mathbf{m}}$ under fluctuating conditions than in constant ones. When all the levels are present, no significant effect on $\mathbf{r}_{\mathbf{m}}$ was detected indicating that $\mathbf{r}_{\mathbf{m}}$ was less sensitive to low temperatures, whatever the temperature and pattern of its management.

\section{Progeny sex-ratio}

The proportion of females in the $\mathrm{F} 1$ generation ranged from 0.42 to 0.55 at $7^{\circ} \mathrm{C}$, from 0.40 to 0.51 at $4^{\circ} \mathrm{C}$, and from 0.37 to 0.57 at $0^{\circ} \mathrm{C}$. The nested analysis of deviance showed a significant effect of thermal regime $\left(\chi_{2}^{2}=91.31, p<0.001\right)$. The control, the treatment $0 \mathrm{C} 1$ and the 
fluctuating treatments displayed a higher female sex-ratio than all other storages at constant temperature. The factor temperature, nested in thermal regime was also significant $\left(\chi^{2}{ }_{4}=18.28, p\right.$ $<0.001)$ whereas the factor storage duration was not $\left(\chi_{2}^{2}=4.49, p=0.11\right)$. The interaction temperature-storage duration, however, was highly significant $\left(\chi_{4}^{2}=26.54, p<0.001\right)$ indicating that the effect of temperature depends on storage duration. The two levels under fluctuating conditions showed an increasing sex-ratio from $0^{\circ} \mathrm{C}$ to $4^{\circ} \mathrm{C}$ and from $4^{\circ} \mathrm{C}$ to $7^{\circ} \mathrm{C}$. Conversely, the patterns under constant temperature conditions differ in function of the storage duration. At $0^{\circ} \mathrm{C}$, the female sex-ratio was high and not significantly different from the control. At $4^{\circ} \mathrm{C}$ the sexratio was very low, and at $7^{\circ} \mathrm{C}$ it was higher. In the opposite, after two weeks of storage, the females exhibited a very low female sex-ratio in their progeny at $0^{\circ} \mathrm{C}$, and higher values at $4^{\circ} \mathrm{C}$ and $7^{\circ} \mathrm{C}$. The difference $0 \mathrm{C} 1-0 \mathrm{C} 2$ is large and significant, $4 \mathrm{C} 1$ and $4 \mathrm{C} 2$ do not differ significantly, neither do $4 \mathrm{C} 1$ and $7 \mathrm{C} 1$, nor $4 \mathrm{C} 2$ and 7C2. In summary, the fluctuating treatments induced a lower decrease in sex-ratio than the constant ones. The proportion of males also increased with the decrease in temperatures and the duration of cold exposure, with the exception of the $0 \mathrm{C} 1$ treatment which was the only one that do not differ significantly from the control.

\section{Discussion}

Effect of exposure to low temperature and duration on development time, emergence and fecundity

Surprisingly, although demographic parameters were expected to be affected by low temperatures, the constant temperature treatment at $0^{\circ} \mathrm{C}$ over one week showed no significant difference to the control group at $20^{\circ} \mathrm{C}$. The net reproductive rate $\left(\mathbf{R}_{\mathbf{0}}\right)$ and the cumulative fecundity decreased significantly for all treatments except $0 \mathrm{C} 1$. Our hypothesis is that a 
temperature of $0^{\circ} \mathrm{C}$ over one week blocked the metabolic rate completely without any physiological damage or any increase in fat consumption which otherwise would have led to a reduction in fecundity. Interesting results were found after a constant and fluctuating exposure at $0^{\circ} \mathrm{C}$ for 4 weeks (see more in Ismail et al. 2013).

Our results showed that development continues in the constant treatments at $7^{\circ} \mathrm{C}$ and $4{ }^{\circ} \mathrm{C}$. According to our prediction, $4^{\circ} \mathrm{C}$ is supposed to be below the $\mathbf{T}_{\mathbf{0}}$, and so development should be stopped, but this was not the case, at least for our strain of $A$. ervi. Moreover, this $\mathrm{T}_{0}$ value was estimated by Sigsgaard (2000) using the "x-intercept" method (Campbell et al. 1974), which determined that the relation between $\mathrm{y}=$ development rate and $\mathrm{x}=$ the temperature is linear. This assumption might overestimate the $\mathbf{T}_{\mathbf{0}}$, because this relationship is not linear for low temperatures (Walgama and Zalucki 2006). So, the development rate at low temperatures is not well known. Similar results were obtained by Frère et al. (2011). Whatever the temperature, the emergence rate after two weeks of exposure to low temperatures remains high and not significantly different from the control. This indicates that there are probably few lethal damages during that period, confirming previous results (Ismail et al. 2012; Ismail et al. 2010).

\section{How to choose demographic indicators?}

In the context of biological control, the choice of the most appropriate demographic parameters to assess the immediate impact of a release of parasitoids is of tremendous importance, particularly when an impact of storage on fitness traits is expected. The originality of this study is to compare the practical consequences of low temperature treatments on different demographic indicators. For instance, only a few studies measured the demographic parameters after the storage. Chen et al. (2008a) used the $\mathbf{R}_{\mathbf{0}}$ to underline the decrease in population growth of the F1 generation of the parasitoid Gonatocerus ashmeadi after 20 days of adult storage at $10^{\circ} \mathrm{C}$. Chen et al. (2008b) 
calculated $\mathbf{r}_{\mathbf{m}}$ and $\mathbf{R}_{\mathbf{0}}$ to present the decrease in population growth of the adult parasitoid $G$. ashmeadi, after they had been stored at immature stage for 30 days using a cycling fluctuating storage temperature regime under $4.5,6$ and $7.2^{\circ} \mathrm{C}$ but with no additional effect on the $\mathrm{F} 1$ generation. On the other hand, Chen et al. (2011) used only the cumulative fecundity to present the decrease in population growth of the parasitoid Habrobracon hebetor after 10 days at $5^{\circ} \mathrm{C}$ of the parental storage.

The poor sensitivity of $\mathbf{r}_{\mathbf{m}}$ to low temperature storage might suggest that the population growth is not strongly affected by the storage, a point that was raised by Ismail et al (2013). This is not the case, because the use of $r_{m}$ parameters obtained for the prediction of the population growth, under stressful conditions, was only valuable if these conditions were continuously applied to subsequent generations. Moreover, the value of $\mathbf{r}_{\mathbf{m}}$ is indicative of the population growth only when the population had reached a stable age structure (Carey 1993) which is obviously not the case for a single stage mass release. $\mathbf{R}_{\mathbf{0}}$ is closer to the original definition of fitness by Haldane (1932): the expectation of the number of viable and reproductive offspring. Indeed, $\mathbf{R}_{\mathbf{0}}$ gives the total offspring expected to be produced by a female during its life. Thus $\mathbf{R}_{\mathbf{0}}$ represents a more immediate prediction of the increase of the population than $\mathbf{r}_{\mathbf{m}}$, which is desirable for practical use in a biological control context. The cumulative fecundity curves correspond to the mean distribution of eggs a female can lay during its life. In particular the value of the inflection point (a) gives an accurate estimate of the moment of the peak of fecundity, which is an essential determinant of the intensity of the population growth. $\mathbf{R}_{\mathbf{0}}$ and the cumulative fecundity therefore reflect the potential of growth in an inundative release context better than $\mathbf{r}_{\mathbf{m}}$. For instance, it appears that the treatments $(7 \mathrm{C} 2,4 \mathrm{C} 1,4 \mathrm{C} 2$, and $0 \mathrm{~F} 1)$ provoking the highest reduction in fecundity compared to control, also inflected at a younger age (Table 2). This earlier peak in fecundity is a compensatory effect on the rapidity of the population growth, and 
illustrates the probably a trade-off between the maximum number of eggs that can be laid daily and the precocity of the peak of fecundity. In consequence, the $\mathbf{r}_{\mathbf{m}}$ value of the $4 \mathrm{C} 2$ treatment remained similar to the control (0.239 and 0.232 respectively) whereas a reduction of $30 \%$ in cumulative fecundity was observed ( $\mathrm{K}$ value $=37.10$ against 52.88 for the control). A simulation of population growth using the $\mathbf{r}_{\mathbf{m}}$ value under stress would therefore not make much sense. We suggest the use of the emergence rate, $\mathbf{R}_{\mathbf{0}}$ and the cumulative fecundity curves of first generation (including $\mathbf{K}$ and $\mathbf{a}$ parameters) to evaluate the immediate effects of the release of stored parasitoids in biological control. The $\mathbf{R}_{\mathbf{0}}$ and the cumulative fecundity and the inflection point may be considered as convenient proxies for immediate fitness (Huey and Berrigan 2001).

\section{Effect of fluctuating thermal regimes}

Fluctuating regimes at the three temperatures $\left(7,4\right.$ and $\left.0^{\circ} \mathrm{C}\right)$ still allow the development of the parasitoids inside the mummies as a clear reduction of development time once replaced at $20^{\circ} \mathrm{C}$ is observed in comparison to the control. This reduction may reach 4 days at $7^{\circ} \mathrm{C}$. Furthermore, it appears that the fluctuating exposure alter the cumulative fecundity or the $\mathbf{R}_{\mathbf{0}}$ less than at constant exposure (except for the treatment $0 \mathrm{C} 1$ discussed above). It is known that the growth rate of insects can be affected by the daily fluctuations in temperature more than by the constant temperatures such as in the field environments (Brakefield and Kesbeke 1997; Brakefield and Mazzotta 1995).

\section{Practical applications in biological control}

The values of Tc would give useful information concerning the expected time to adult emergence after exposure to low temperatures. In practice, for storage in case of mass release, a reduction of the development time of mummies complicates the distribution of mummies to farmers. 
However, the knowledge of the relation between fluctuating temperature and reduction of development time will allow for the management of this difficulty by releasing individuals whose demographic capacities are less impaired than those under storage at constant temperature.

Moreover, this concern may be reduced if boxes where the mummies are kept are provided with honey during the delivery. This could even be an opportunity to obtain mating before release. This is an important point for practical application.

In conclusion, an effective storage technique should result in a high emergence rates, and should no affect fecundity and reproductive activity (Ismail et al. 2010; Tauber et al. 1993). In our case the best result was obtained at $0^{\circ} \mathrm{C}$ for 1 week and could be a suitable treatment to store the mummies of A. ervi without any deleterious effects on the growth rate for a short period. In the current study, observed mating and laying behaviour are very encouraging features for further commercial issues. 


\section{References}

Amir-Maafi M, Chi H (2006) Demography of Habrobracon hebetor (Hymenoptera: Braconidae) on two pyralid hosts (Lepidoptera: Pyralidae). Ann Entomol Soc Am 99:84-90

Amiri A, Talebi AA, Zamani AA, Kamali K (2010) Effect of temperature on demographic parameters of the hawthorn red midget moth, Phyllonorycter corylifoliella, on apple. $\mathbf{J}$ Insect Sci 10:134

Andrewartha HG, Birch LC (1954) The Distribution and Abundance of Animals. University of Chicago Press, Chicago, USA.

Angilletta MJ (2009) Thermal Adaptation: A Theoretical and Empirical Synthesis. Oxford University Press, Oxford

Atlihan R, Chi H (2008) Temperature-dependent development and demography of Scymnus subvillosus (Coleoptera: Coccinellidae) reared on Hyalopterus pruni (Homoptera: Aphididae). J Econ Entomol 101:325-333

Birch LC (1948) The intrinsic rate of natural increase of an insect population. Journal of Animal Ecology 17:15-26

Blanco CA, Portilla M, Abel CA, Winters H, Ford R, Streett D (2009) Soybean flour and wheat germ proportions in artificial diet and their effect on the growth rates of the tobacco budworm, Heliothis virescens. J Insect Sci 9:59

Boivin G, Hance T, Brodeur J (2012) Aphid parasitoids in biological control. Can J Plant Sci 92:1-12

Brakefield PM, Kesbeke F (1997) Genotype-environment interactions for insect growth in constant and fluctuating temperature regimes. P Roy Soc B-Biol Sci 264:717-723

Brakefield PM, Mazzotta V (1995) Matching field and laboratory environments - effects of neglecting daily temperature-variation on insect reaction normS. J Evol Biol 8:559-573 
Bueno R, van Cleave HW (1997) The effect of temperature and host density on the reproduction of Aphelinus perpallidus (Hymenoptera: Aphelinidae). Southwest Entomol 22:29-37

Campbell A, Frazer BD, Gilbert N, Gutierrez AP, Mackauer M (1974) Temperature requirements of some aphids and their parasites. J Appl Ecol 11:431-438

Carey JR (1993) Applied Demography for Biologists with Special Emphasis on Insects. Oxford University Press, New York, USA.

Chen HL, Opit GP, Sheng P, Zhang HY (2011) Maternal and progeny quality of Habrobracon hebetor Say (Hymenoptera: Braconidae) after cold storage. Biol Control 58:255-261

Chen WL, Leopod RA, Boetel MA (2008a) Cold Storage of Adult Gonatocerus ashmeadi (Hymenoptera: Mymaridae) and Effects on Maternal and Progeny Fitness. J Econ Entomol 101:1760-1770

Chen WL, Leopold RA, Harris MO (2008b) Cold storage effects on maternal and progeny quality of Gonatocerus ashmeadi Girault (Hymenoptera: Mymaridae). Biol Control 46:122-132

Chi H (1988) Life-table analysis incorporating both sexes and variable development rates among individuals. Environ Entomol 17:26-34

Chi H, Su HY (2006) Age-stage, two-sex life tables of Aphidius gifuensis (Ashmead) (Hymenoptera: Braconidae) and its host Myzus persicae (Sulzer) (Homoptera: Aphididae) with mathematical proof of the relationship between female fecundity and the net reproductive rate. Environ Entomol 35:10-21

Colinet H, Boivin G (2011) Insect parasitoids cold storage: A comprehensive review of factors of variability and consequences. Biol Control 58:83-95

Colinet H, Renault D, Hance T, Vernon P (2006) The impact of fluctuating thermal regimes on the survival of a cold exposed parasitic wasp, Aphidius colemani. Physiol Entomol $31: 234-240$ 
Efron B (1989) Overdispersion estimated based on the method of of asymmetric maximum likelihood. Stanford University, Stanford, California

Ehler LE (1990) Introduction strategies in biological control of insects. In: Mackauer M, Ehler LE, Roland J (eds) Critical Issues in Biological Control Intercept. Andover, UK, pp 111134

Frère I, Balthazar C, Sabri A, Hance T (2011) Improvement in the cold storage of Aphidius ervi (Hymenoptera : Aphidiinae). Eur J Environ Sci 1:33-40

Haldane JBS (1932) The causes of evolution. Longmans Green, London

Hance T, Nibelle D, Lebrun P, van Impe G, van Hove C (1994) Selection of Azolla forms resistant to the water lily aphid, Rhopalosiphum nymphaeae - Susceptibility of Azolla forms to Rhopalosiphum nymphaeae. Entomol Exp Appl 70:19-25

Hance T, van Baaren J, Vernon P, Boivin G (2007) Impact of extreme temperatures on parasitoids in a climate change perspective. Annu Rev Entomol 52:107-126

Huey RB, Berrigan D (2001) Temperature, demography, and ectotherm fitness. Am Nat 158:204210

Ismail M, van Baaren J, Hance T, Pierre JS, Vernon P (2013) Stress intensity and fitness in the parasitoid Aphidius ervi (Hymenoptera: Braconidae): temperature below the development threshold combined with a fluctuating thermal regime is a must. Ecol Entomol 38: 355363.

Ismail M, Vernon P, Hance T, Pierre JS, van Baaren J (2012) What are the possible benefits of small size for energy-constrained ectotherms in cold stress conditions? Oikos 121:20722080

Ismail M, Vernon P, Hance T, van Baaren J (2010) Physiological costs of cold exposure on the parasitoid Aphidius ervi, without selection pressure and under constant or fluctuating 
temperatures. Biocontrol 55:729-740

Kennedy JS, VanImpe G, Hance T, Lebrun P (1996) Demecology of the false spider mite, Brevipalpus phoenicis (Geijskes) (Acari, Tenuipalpidae). J Appl Entomol 120:493-499

Leopold RA, Rojas RR, Atkinson PW (1998) Post pupariation cold storage of three species of flies: Increasing chilling tolerance by acclimation and recurrent recovery periods. Cryobiology 36:213-224

Levie A, Vernon P, Hance T (2005) Consequences of acclimation on survival and reproductive capacities of cold-stored mummies of Aphidius rhopalosiphi (Hymenoptera: Aphidiinae). J Econ Entomol 98:704-708

Mawela KV, Kfir R, Krueger K (2013) Effect of temperature and host species on parasitism, development time and sex ratio of the egg parasitoid Trichogrammatoidea lutea Girault (Hymenoptera: Trichogrammatidae). Biol Control 64:211-216

Meyer JS, Ingersoll CG, McDonald LL, Boyce MS (1986) Estimating uncertainty in population growth rates - jackknife vs bootstrap techniques. Ecology 67:1156-1166

Moiroux J, Delava E, Fleury F, Van Baaren J (2013) Local adaptation of a Drosophila parasitoid: habitat-specific differences in thermal reaction norms. J Evolution Biol 26:1108-1116

Nunez-Campero SR, Ovruski SM, Aluja M (2012) Survival analysis and demographic parameters of the pupal parasitoid Coptera haywardi (Hymenoptera: Diapriidae), reared on Anastrepha fraterculus (Diptera: Tephritidae). Biol Control 61:40-46

Omer AD, Johnson MW, Tabashnik BE (1996) Demography of the leafminer parasitoid Ganaspidium utilis Beardsley (Hymenoptera: Eucoilidae) at different temperatures. Biol Control 6:29-34

Price PW, Denno RF, Eubanks MD, Finke DL, Kaplan I (2011) Insect Ecology: Behavior, Populations and Communities. Cambridge University Press, New York, USA. 
R Development Core Team. 2008. R: A Language and Environment for Statistical Computing. R Foundation for Statistical Computing: Vienna, Austria. ISBN 3-900051-07-0. Available online at: http://www.R-project.org. Accessed 31 January 2013.

Roy M, Brodeur J, Cloutier C (2003) Effect of temperature on intrinsic rates of natural increase (rm) of a coccinellid and its spider mite prey. Biocontrol 48:57-72

Sigsgaard L (2000) The temperature-dependent duration of development and parasitism of three cereal aphid parasitoids, Aphidius ervi, A. rhopalosiphi, and Praon volucre. Entomol Exp Appl 95:173-184

Stilmant D, van Bellinghen C, Hance T, Boivin G (2008) Host specialization in habitat specialists and generalists. Oecologia 156:905-912

Tauber MJ, Tauber CA, Gardescu S (1993) Prolonged storage of Chrysoperla carnea (Neuroptera: Chrysopidae). Environ Entomol 22:843-848

van Baaren J, Outreman Y, Boivin G (2005) Effect of low temperature exposure on oviposition behaviour and patch exploitation strategy in parasitic wasps. Anim Behav 70:153-163

von Bertalanffy L, Untersuchungen über die Gesetzlichkeit des Wachstums I. Allgemeine Grundlagen der Theorie; mathematische und physiologische Gesetzlichkeiten des Wachstums bei Wassertieren. Arch Entwicklungsmech 131: 613-652 (1934).

Walgama RS, Zalucki MP (2006) Evaluation of different models to describe egg and pupal development of Xyleborus fornicatus Eichh. (Coleoptera: Scolytidae), the shot-hole borer of tea in Sri Lanka. Insect Sci 13:109-118

Yang TC, Chi H (2006) Life tables and development of Bemisia argentifolii (Homoptera : Aleyrodidae) at different temperatures. J Econ Entomol 99:691-698

Yu JZ, Chi H, Chen BH (2013) Comparison of the life tables and predation rates of Harmonia dimidiata (F.) (Coleoptera: Coccinellidae) fed on Aphis gossypii Glover (Hemiptera: 
Aphididae) at different temperatures. Biol Control 64:1-9 
Table 1: Summary of the 12 applied low temperature treatments and control, and the emergence rates $\pm S E_{(S E}$ $=\sqrt{ }(\mathbf{p q} / \mathbf{n})$ after each treatment.

\begin{tabular}{|c|c|c|c|c|}
\hline Temperature & Duration & Regime & Treatment & Emergence rate \% \\
\hline $20^{\circ} \mathrm{C}$ & Until emergence & Constant & 20C (115 mummies) & $97.39 \pm 1.59$ \\
\hline \multirow{4}{*}{$7^{\circ} \mathrm{C}$} & \multirow{2}{*}{ Constant } & 1 week & 7C1 (111 mummies) & $94.59 \pm 2.26$ \\
\hline & & 2 weeks & 7C2 (114 mummies) & $93.86 \pm 2.40$ \\
\hline & \multirow{2}{*}{ Fluctuant } & 1 week & 7F1 (108 mummies) & $97.22 \pm 1.64$ \\
\hline & & 2 weeks & 7F2 (107 mummies) & $96.26 \pm 1.90$ \\
\hline \multirow{4}{*}{$4^{\circ} \mathrm{C}$} & \multirow{2}{*}{ Constant } & 1 week & 4C1 (112 mummies) & $91.96 \pm 2.72$ \\
\hline & & 2 weeks & 4C2 (124 mummies) & $88.71 \pm 3.16$ \\
\hline & \multirow{2}{*}{ Fluctuant } & 1 week & 4F1 (101 mummies) & $97.03 \pm 1.70$ \\
\hline & & 2 weeks & 4F2 (110 mummies) & $95.46 \pm 2.08$ \\
\hline \multirow{4}{*}{$0^{\circ} \mathrm{C}$} & \multirow{2}{*}{ Constant } & 1 week & 0C1 (126 mummies) & $95.24 \pm 2.13$ \\
\hline & & 2 weeks & 0C2 (166 mummies) & $80.12 \pm 3.99$ \\
\hline & \multirow{2}{*}{ Fluctuant } & 1 week & OF1 (101 mummies) & $95.05 \pm 2.17$ \\
\hline & & 2 weeks & 0F2 (120 mummies) & $94.17 \pm 2.34$ \\
\hline
\end{tabular}


Table 2. The cumulative fecundity with $(\mathrm{K})$ indicating the maximum of offspring after one generation and the $\log (3) / a$ indicating the inflection point, and progeny sex-ratio progeny expressed as the proportion of females for G1. Data are presented as mean $\pm \mathrm{SE}_{(\mathrm{SE}=\operatorname{standard} \text { deviation } / \sqrt{ } \mathrm{n})}$. The number between the brackets is the number of repetitions. Different letters indicate the significant differences among the treatments $(\mathbf{p}=0.004)$.

\begin{tabular}{|c|c|c|c|}
\hline Treatment & $\begin{array}{l}\text { The cumulative fecundity } \\
\text { (K value) }\end{array}$ & $\begin{array}{l}\text { The inflection point } \\
(\log (3) / a)\end{array}$ & Progeny sex-ratio \\
\hline $20^{\circ} \mathrm{C}(15)$ & $52.88 \pm 0.33 \mathrm{ab}$ & $2.72 \pm 0.01 \mathrm{bc}$ & $0.57 \pm 0.01 \mathrm{a}$ \\
\hline 7C1 (13) & $35.64 \pm 0.33 \mathrm{e}$ & $2.22 \pm 0.04 \mathrm{de}$ & $0.47 \pm 0.01 \mathrm{cde}$ \\
\hline $7 C 2(13)$ & $32.50 \pm 0.31 \mathrm{ef}$ & $2.10 \pm 0.02$ ef & $0.42 \pm 0.01 \mathrm{de}$ \\
\hline $7 F 1(15)$ & $47.15 \pm 0.32 \mathrm{c}$ & $2.05 \pm 0.01 \mathrm{ef}$ & $0.55 \pm 0.01 \mathrm{ab}$ \\
\hline $7 F 2(13)$ & $36.61 \pm 0.20 \mathrm{de}$ & $2.40 \pm 0.02 \mathrm{~d}$ & $0.51 \pm 0.02 \mathrm{abcd}$ \\
\hline 4C1 (13) & $28.74 \pm 0.18 \mathrm{f}$ & $2.18 \pm 0.02 \mathrm{e}$ & $0.40 \pm 0.01 \mathrm{e}$ \\
\hline 4C2 (13) & $37.10 \pm 0.45 \mathrm{de}$ & $1.82 \pm 0.03 \mathrm{~g}$ & $0.45 \pm 0.02 \mathrm{cde}$ \\
\hline 4F1 (13) & $48.24 \pm 0.48 \mathrm{bc}$ & $2.85 \pm 0.05 \mathrm{~b}$ & $0.51 \pm 0.02 \mathrm{abc}$ \\
\hline $4 \mathrm{~F} 2(13)$ & $41.98 \pm 0.40 \mathrm{~d}$ & $2.30 \pm 0.03 \mathrm{de}$ & $0.47 \pm 0.01 \mathrm{bcd}$ \\
\hline 0C1 (6) & $54.66 \pm 0.81 \mathrm{a}$ & $2.50 \pm 0.03 \mathrm{~cd}$ & $0.57 \pm 0.01 \mathrm{ab}$ \\
\hline $0 \mathrm{C} 2(7)$ & $37.55 \pm 0.76 \mathrm{de}$ & $2.69 \pm 0.08 \mathrm{bc}$ & $0.37 \pm 0.04 \mathrm{de}$ \\
\hline 0F1 (6) & $36.89 \pm 0.81 \mathrm{de}$ & $1.86 \pm 0.05 \mathrm{fg}$ & $0.48 \pm 0.03 \mathrm{abcd}$ \\
\hline $0 \mathrm{~F} 2(6)$ & $38.16 \pm 0.89 \mathrm{de}$ & $3.41 \pm 0.17 \mathrm{a}$ & $0.48 \pm 0.02 \mathrm{abcd}$ \\
\hline
\end{tabular}


Table 3. Demographic growth parameters in adults emerged after mummy storage, according to the storage temperature, duration and thermal regime. Data are presented as mean $\pm \mathrm{SE}$, obtained by the Jackknife method. Tc: development time (storage period was not taken into account), $R_{0}$ : the net reproductive rate and $r_{m}$ : the intrinsic rate of increase. The number between the brackets is the number of repetitions. Different letters indicate the significant differences among the treatments $(p=0.004)$.

\begin{tabular}{cccc}
\hline \multirow{2}{*}{ Treatment } & \multicolumn{3}{c}{ Demographic parameters } \\
& Tc & $\mathbf{R}_{\mathbf{0}}$ & $\mathbf{r}_{\mathbf{m}}$ \\
\hline $20^{\circ} \mathrm{C}(15)$ & $17.44 \pm 0.01 \mathrm{ahi}$ & $51.94 \pm 0.57 \mathrm{a}$ & $0.232 \pm 0.010 \mathrm{a}$ \\
\hline 7C1 (13) & $15.99 \pm 0.04 \mathrm{cdhi}$ & $35.25 \pm 0.60 \mathrm{~d}$ & $0.230 \pm 0.019 \mathrm{a}$ \\
7C2 (13) & $14.76 \pm 0.02 \mathrm{fhi}$ & $31.49 \pm 0.53 \mathrm{f}$ & $0.240 \pm 0.016 \mathrm{a}$ \\
7F1 (15) & $15.89 \pm 0.02 \mathrm{dehi}$ & $47.47 \pm 0.28 \mathrm{~b}$ & $0.249 \pm 0.008 \mathrm{a}$ \\
7F2 (13) & $14.14 \pm 0.02 \mathrm{ghi}$ & $36.62 \pm 0.32 \mathrm{~d}$ & $0.262 \pm 0.009 \mathrm{a}$ \\
\hline 4C1 (13) & $16.80 \pm 0.02 \mathrm{bhi}$ & $27.86 \pm 0.33 \mathrm{~g}$ & $0.201 \pm 0.009 \mathrm{a}$ \\
4C2 (13) & $14.56 \pm 0.05 \mathrm{adfhi}$ & $36.73 \pm 0.84 \mathrm{~d}$ & $0.239 \pm 0.014 \mathrm{a}$ \\
4F1 (13) & $16.04 \pm 0.03 \mathrm{chi}$ & $38.01 \pm 0.55 \mathrm{~cd}$ & $0.242 \pm 0.009 \mathrm{a}$ \\
4F2 (13) & $14.28 \pm 0.03 \mathrm{ehi}$ & $41.33 \pm 0.73 \mathrm{c}$ & $0.254 \pm 0.016 \mathrm{a}$ \\
\hline 0C1 (6) & $17.32 \pm 0.04 \mathrm{~h}$ & $54.92 \pm 1.81 \mathrm{a}$ & $0.236 \pm 0.009 \mathrm{a}$ \\
0C2 (7) & $17.52 \pm 0.06 \mathrm{~h}$ & $38.07 \pm 1.75 \mathrm{~cd}$ & $0.224 \pm 0.011 \mathrm{a}$ \\
0F1 (6) & $16.28 \pm 0.09 \mathrm{i}$ & $38.58 \pm 2.10 \mathrm{~cd}$ & $0.242 \pm 0.021 \mathrm{a}$ \\
0F2 (6) & $16.04 \pm 0.11 \mathrm{i}$ & $37.42 \pm 2.36 \mathrm{~cd}$ & $0.235 \pm 0.018 \mathrm{a}$ \\
\hline
\end{tabular}

